\title{
Failure Reason Analysis of Subsea BOP in Deepwater on Bayesian network
}

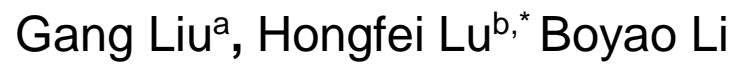 \\ China University of Petroleum (East China), Qingdao, Shandong, 266580, China \\ alg87323@126.com, bpengyoukele8@163.com \\ ${ }^{*}$ Corresponding author
}

Keywords: deepwater BOP system; Bayesian network; risk identification; common cause failure.

\begin{abstract}
Deepwater drilling is the key of offshore oil and gas exploration and development. Deepwater BOP system is the key equipment which ensure safety in drilling operation. In order to prevent deepwater well control accidents and guarantee deepwater drilling undersafe and efficient conditions, Bayesian network and FTA methods were comprehensive used to analyze risk of subsea BOP. During the analysis, both of human error and component failure were considered to make the calculation more objective. 6 main failure reasons such as wellhead connector failure, power system failure and accumulator failure are obtained. According to the calculation some improvement measures or suggestions have been proposed for the optimization of deepwater BOP system.
\end{abstract}

\section{基于贝叶斯网络的深水水下防喷器失效原因分析$$
\text { 刘刚a，卢鸿飞b, }{ }^{*} \text {, 李伯尧 }
$$$$
\text { 中国石油大学 (华东) 石油工程学院, 青岛, 山东, 中国 }
$$$$
\text { alg87323@126.com, bpengyoukele8@163.com }
$$ \\ 通讯作者}

关键词：深水防喷器；贝叶斯网络；风险识别；共因失效

中文摘要. 深水钻井是海上油气资源勘探开发的龙头, 而深水防喷器组是保证钻井作业安全 最关键的设备。为预防深水井控事故, 保障深水钻井安全高效运行, 综合运用故障树 (FTA) 分析法和贝叶斯网络 (BN) 对近年工程中普遍使用的深水水下防喷器组结构进行风险分析。 在分析过程中考虑了人因失误和组件共因失效的影响, 计算结果更为客观, 得出井口连接器 失效、电力系统失效、蓄能器失效等 6 个主要失效原因并有针对性地提出改进措施或建议, 为 深水水下防喷器组合的优选提供参考。

\section{1. 引言}

随着陆地和浅海油气资源的枯竭，深水已成为各国和各大油公司勘探开发的重点区域。 在我国，南海海域蕴藏的油气资源约占全国油气资源总量的三分之一，并且其中70\%的资源 量储存在深海海域 ${ }^{11}$ 。所以安全高效地开发深水油气资源对保障我国能源安全、实现可持续 发展具有重大意义 ${ }^{[2]}$ 。 
防喷器作为重要的井控装备对于一口井的安全钻进非常重要, 尤其是 “深水地平线号” 事故放生以后, 人们更加重视对防喷器的风险分析研究。国内虽然起步较晚, 但是对深水防 喷器组也有了一定的研究, 例如, 曹式敬等利用圥余法对 “海洋石油 981 ” 深水防喷器系统进 行可靠性分析, 并提出在原有防喷器结构的基础上再增加一个剪切闸板的建议 ${ }^{[3]}$ 。蔡宝平等 利用马尔科夫链对深水防喷器组的可靠性进行研究, 结果表明增加一个水下闸板防喷器对可 靠性的提高并不明显, 而防喷器控制系统的维修对防喷器可靠性影响最大。

本文在前人研究的基础上，经过统计、整理ExproSoft发布的美国墨西哥湾外大陆架近年 来的深水防喷器失效事故, 结合相关文献、报告 ${ }^{[4-7]}$ 和专家经验, 利用贝叶斯网络双向分析的 特点, 对水下防喷器组进行风险分析, 并在分析过程中考虑了人因失误和组件共因失效的影 响, 以期得出更加客观的计算结果、找出主要失效原因, 为深水水下防喷器组合的优选提供 参考。

\section{2. 深水水下防喷器组结构确定}

统计分析在墨西哥湾工作的 42 个深水钻井平台 ${ }^{[8]}$ （其中7个钻井船和35个半潜式钻井平 台）配备的水下防喷器组合形式及对应的最大作业水深, 结果如表1所示。从表中可以看出绝 大多数钻井平台配备 2 个环形防喷器, 且作业水深越大, 闸板防喷器配置越齐全。根据调查结 果, 确立以最大水深10000ft的防喷器组合作为风险分析对象, 并按照IADC的最新建议 ${ }^{[9]}$, 下 部隔水管总成将包含一个液压连接器和两个环形防喷器, 原因是下部隔水管总成可能用于应 急救援过程, 其配备两个环形防喷器有助于更好的控制井口压力; 下部防喷器组中包括一个 钻杆剪切闸板、一个套管剪切闸板、三个可变径闸板和一个测试闸板。具体结构如图1所示:

\begin{tabular}{|c|c|c|c|c|c|c|c|c|c|c|c|c|c|}
\hline \multirow[b]{2}{*}{$\begin{array}{l}\text { 序 } \\
\text { 号 }\end{array}$} & \multirow[b]{2}{*}{ 类型 } & \multirow[b]{2}{*}{$\begin{array}{l}\text { 定位 } \\
\text { 方式 }\end{array}$} & \multirow[b]{2}{*}{$\begin{array}{c}\text { BOP } \\
\text { 制造商 }\end{array}$} & \multirow[b]{2}{*}{ 控制系统 } & \multirow[b]{2}{*}{$\begin{array}{c}\text { 作业水深 } \\
(\mathrm{ft})\end{array}$} & \multirow[b]{2}{*}{$\begin{array}{l}\text { 环形 } \\
\text { 数量 }\end{array}$} & \multicolumn{7}{|c|}{ 闸板数量 } \\
\hline & & & & & & & 盲板 & $\begin{array}{l}\text { 剪切 } \\
\text { 套管 }\end{array}$ & 变径 & 固定 & 套管 & 测试 & 总计 \\
\hline 1 & 船 & 动力 & Hydril & 多路电液 & 5000 & 2 & 1 & 1 & 2 & & & 1 & 5 \\
\hline 2 & 船 & 动力 & Cameron & 多路电液 & 7000 & 2 & 2 & 1 & 3 & & & & 6 \\
\hline 3 & 船 & 动力 & Cameron & 多路电液 & 9000 & 2 & 2 & & 2 & & & 1 & 5 \\
\hline 4 & 船 & 动力 & Hydril & 多路电液 & 5000 & 2 & 1 & 1 & 2 & & 1 & 1 & 6 \\
\hline 5 & 船 & 动力 & Hydril & 多路电液 & 8000 & 1 & 2 & & 3 & & & 1 & 6 \\
\hline 6 & 船 & 动力 & Hydril & 多路电液 & 6000 & 2 & 2 & 1 & 2 & & 1 & & 6 \\
\hline 7 & 船 & 动力 & Hydril & 多路电液 & 8000 & 2 & 2 & & 3 & & & 1 & 6 \\
\hline 8 & 半潜 & 针链 & Cameron & 液压先导 & 7000 & 2 & 1 & & 2 & & 1 & & 4 \\
\hline 9 & 半潜 & 针链 & Hydril & 多路电液 & 7000 & 2 & 1 & & 2 & 1 & & & 4 \\
\hline 10 & 半潜 & 针链 & Cameron & 多路电液 & 3000 & 2 & 1 & & 1 & 1 & 1 & & 4 \\
\hline 11 & 半潜 & 动力 & Shaffer & 多路电液 & 10000 & 2 & 2 & & 4 & & & & 6 \\
\hline 12 & 半潜 & 针链 & Shaffer & 液压先导 & 9000 & 2 & 1 & & 3 & & & 1 & 5 \\
\hline 13 & 半潜 & 针链 & Hydril & 液压先导 & 7000 & 2 & 1 & & 3 & & & 1 & 5 \\
\hline 14 & 半潜 & 针链 & Hydril & 液压先导 & 4000 & 2 & 1 & & 2 & & 1 & & 4 \\
\hline 15 & 半潜 & 针链 & Cameron & 液压先导 & 3000 & 2 & 1 & & 2 & 1 & & & 4 \\
\hline 16 & 半潜 & 针链 & Shaffer & 液压先导 & 6000 & 2 & 1 & & 2 & & 1 & & 4 \\
\hline 17 & 半潜 & 针链 & Cameron & 液压先导 & 5000 & 2 & 1 & & 2 & & 1 & & 4 \\
\hline 18 & 半潜 & 针链 & Shaffer & 液压先导 & 5000 & 2 & 1 & & 2 & & 1 & & 4 \\
\hline 19 & 半潜 & 针链 & Hydril & 液压先导 & 3000 & 2 & 1 & & 3 & & & & 4 \\
\hline 20 & 半潜 & 动力 & Hydril & 多路电液 & 6000 & 2 & 1 & 1 & 2 & 1 & & 1 & 6 \\
\hline 21 & 半潜 & 动力 & Hydril & 多路电液 & 8000 & 2 & 1 & 1 & 3 & & & 1 & 6 \\
\hline 22 & 半潜 & 动力 & Hydril & 多路电液 & 7000 & 2 & 1 & 1 & 3 & & & 1 & 6 \\
\hline
\end{tabular}




\begin{tabular}{|c|c|c|c|c|c|c|c|c|c|c|c|c|c|}
\hline 23 & 半潜 & 针链 & Cameron & 液压先导 & 4000 & 2 & 1 & & 2 & & 1 & & 4 \\
\hline 24 & 半潜 & 针链 & Cameron & 多路电液 & 4000 & 2 & 1 & & 2 & & 1 & & 4 \\
\hline 25 & 半潜 & 针链 & Shaffer & 多路电液 & 8000 & 2 & 1 & & 2 & & 1 & & 4 \\
\hline 26 & 半潜 & 针链 & Shaffer & 多路电液 & 10000 & 2 & 1 & 1 & 2 & & 1 & 1 & 6 \\
\hline 27 & 半潜 & 针链 & Shaffer & 多路电液 & 6000 & 2 & 1 & & 3 & & & 1 & 5 \\
\hline 28 & 半潜 & 针链 & Cameron & 液压先导 & 4000 & 1 & 1 & & 3 & & & & 4 \\
\hline 29 & 半潜 & 针链 & Shaffer & 多路电液 & 6000 & 2 & 1 & & 2 & & 1 & & 4 \\
\hline 30 & 半潜 & 针链 & Shaffer & 多路电液 & 6000 & 2 & 1 & & 3 & & & 1 & 5 \\
\hline 31 & 半潜 & 动力 & Cameron & 多路电液 & 9000 & 2 & 1 & & 2 & 1 & & & 4 \\
\hline 32 & 半潜 & 动力 & Cameron & 液压先导 & 5000 & 2 & 1 & 1 & 3 & & & 1 & 6 \\
\hline 33 & 半潜 & 动力 & Cameron & 多路电液 & 7000 & 1 & 1 & 1 & & 2 & & 1 & 5 \\
\hline 34 & 半潜 & 针链 & Cameron & 多路电液 & 3000 & 2 & 1 & & 2 & & 1 & & 4 \\
\hline 35 & 半潜 & 动力 & Cameron & 多路电液 & 7000 & 1 & 1 & 1 & 2 & & 1 & & 5 \\
\hline 36 & 半潜 & 动力 & Cameron & 多路电液 & 7000 & 2 & 1 & 1 & 3 & & & & 5 \\
\hline 37 & 半潜 & 针链 & Cameron & 多路电液 & 8000 & 1 & 1 & & 3 & & & 1 & 5 \\
\hline 38 & 半潜 & 动力 & Hydril & 多路电液 & 7000 & 2 & 2 & 1 & 3 & & & & 6 \\
\hline 39 & 半潜 & 动力 & Hydril & 多路电液 & 7000 & 2 & 1 & 1 & 3 & & & 1 & 6 \\
\hline 40 & 半潜 & 针链 & Cameron & 液压先导 & 3000 & 2 & 1 & & 2 & 1 & & & 4 \\
\hline 41 & 半潜 & 针链 & Hydril & 液压先导 & 4000 & 1 & 1 & & 2 & & 1 & 1 & 5 \\
\hline 42 & 半潜 & 针链 & Hydril & 多路电液 & 7000 & 2 & 1 & & 3 & & & 1 & 5 \\
\hline
\end{tabular}




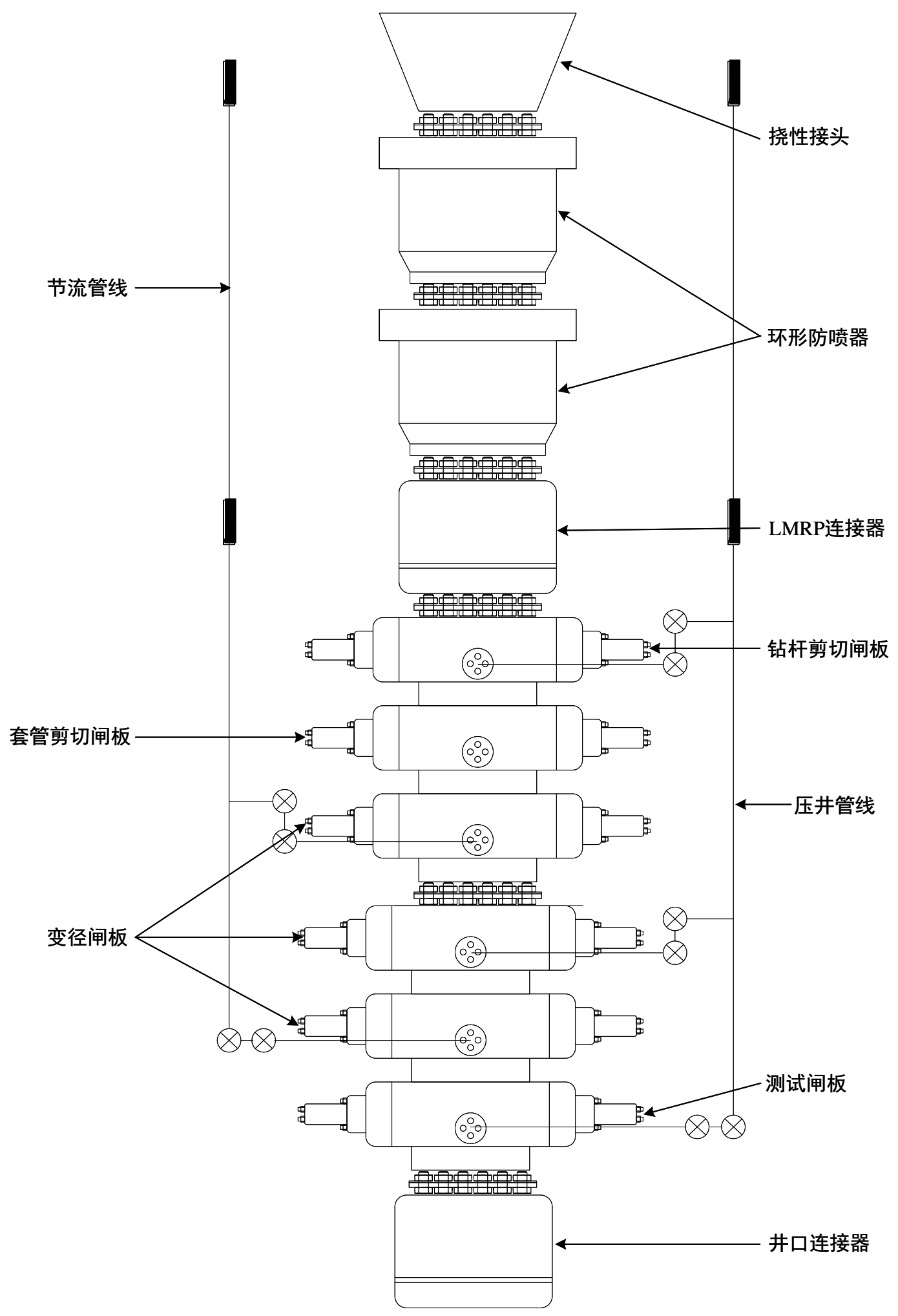

图1 水下防喷器结构

\section{3. 贝叶斯网络建模}

贝叶斯网络建模过程一般分为 3 个步骤, 首先确定根节点, 即识别系统中的风险诱因; 其 次判断各节点之间的相对关系, 用有向弧表示; 最后根据各节点的先验概率求解后验概率。 


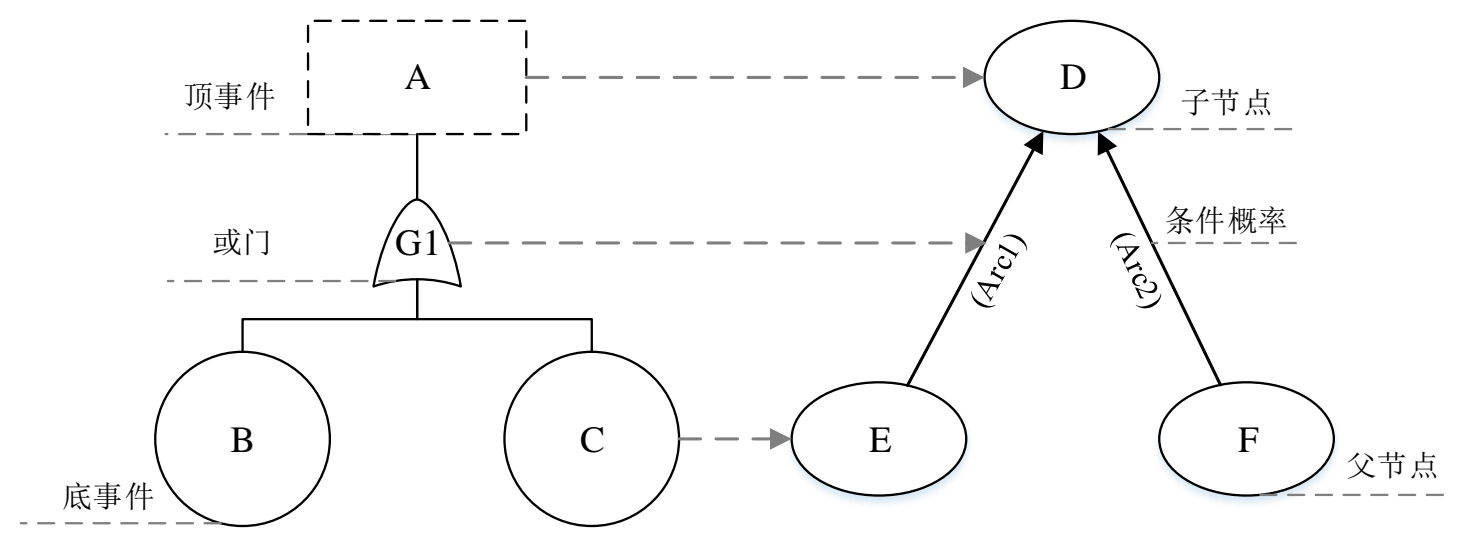

图2 贝叶斯网络映射模型

图2为事故树向贝叶斯网络转化的映射模型，事故树的底事件对应贝叶斯网络的父节点; 顶事件对应贝叶斯网络的子节点; 逻辑门 (与门、或门) 对应贝叶斯网络中的条件概率（不 同逻辑门对应不同的条件概率）。与事故树不同，贝叶斯网络中的条件概率已不是 0 或 1 的简 单关系，而是 $0 \sim 1$ 之间的概率分布，更加符合客观实际 ${ }^{[10]}$

\section{1 风险识别及事故树模型建立}

根据Exprosoft发布的事故数据和相关文献 ${ }^{[8,11]}$, 识别出 34 个水下防喷器风险诱因, 并以此 为基础, 从水下防喷器失效, 水上和水下控制系统失效、节流/压井管线失效和隔水管/井口连 接装置失效5个方面对水下防喷器组进行风险分析并建立如图4所示的事故树模型。

\section{2 贝叶斯网络模型建立}

在贝叶斯网络的构建中考虑了防喷器组件共因失效的情况。共因失效是指在冗余系统中 由单一事件引发的某一系统中所有圥余组件失效的情况 ${ }^{[12]}$, 在以往的深水防喷器风险分析中 往往假设穴余系统中各部件的失效是相互独立的, 但在实际情况中由于设计、制造、安装和 风险源等因素影响、呪余系统中组件的失效往往具有相关性, 若忽略这部分的影响, 计算结 果将产生一定的误差。故本文利用贝叶斯网络的共因失效分析能力, 在深水防喷器组得风险 分析中考虑共因因素的影响，以期得出更准确的组件失效概率。

贝叶斯网络共因失效分析过程可以分为三个阶段, 首先是确定深水防喷器中的共因失效 组, 然后构建贝叶斯网络模型, 最后输入数据进行计算 ${ }^{[13]}$ 。本文主要确定了水上控制站、水 下控制盒、环形防喷器和闸板防喷器四个共因失效组, 并采用显示模型以图3为例构建贝叶斯 网络模型。图中节点 $\mathrm{B}$ 和节点 $\mathrm{C}$ 表示系统A中的两个几朵不见, 节点I_B和节点I_C分别表示部 件 $\mathrm{B}$ 和部件 $\mathrm{C}$ 单独失效事件, 而节点 $\mathrm{BC}$ 则表示圥余部件 $\mathrm{B}$ 和部件 $\mathrm{C}$ 的共因失效事件。

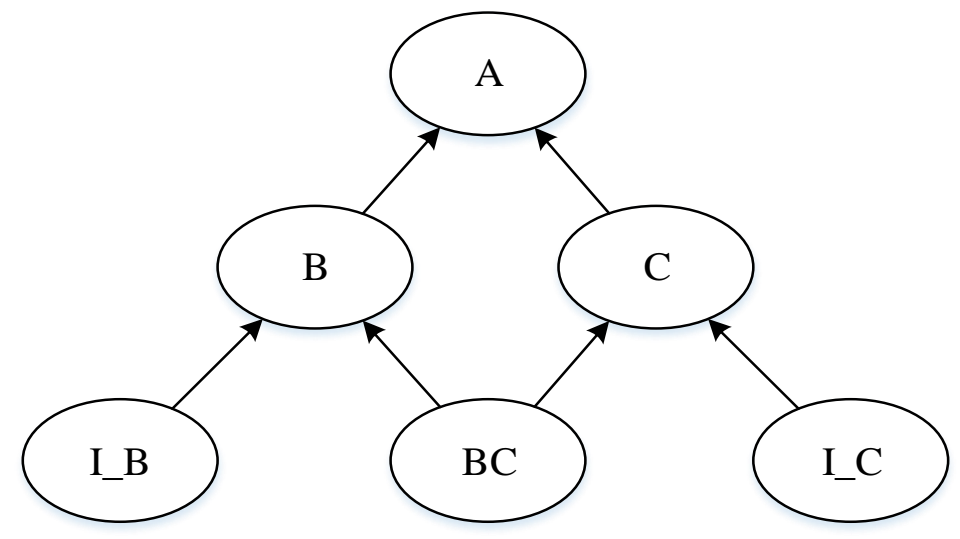

图3 贝叶斯共因失效分析模型 
以事故树向贝叶斯网络映射模型为基础, 并结合贝叶斯网络共因失效分析模型, 将事故 树模型转化为贝叶斯网络模型。
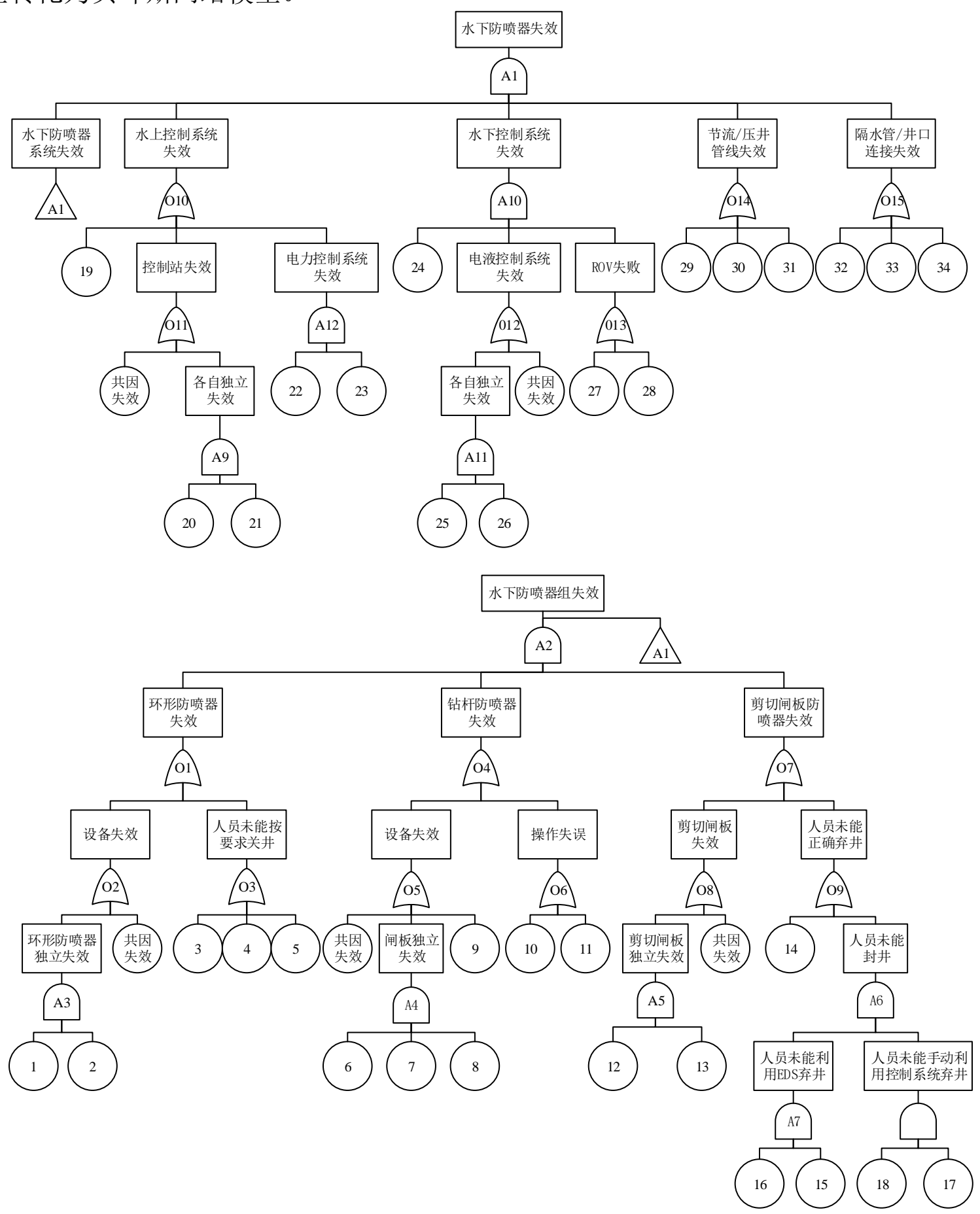

图4 水下防喷器失效事故树模型

\section{4. 贝叶斯网络模型的计算与分析}

\section{1 防喷器组件先验概率的计算}

防喷器组件按工作形式可以分为两类，一类为连续工作形势的组件 (Continous Operating Equipment）, 这些组件在安装后就一直处于工作状态, 例如挠性接头、井口连接器和电力供 应系统等; 另一类为功能性组件 (On-Demand Equipment), 这些组件安装后只有在接收相关 
指令后才处于工作状态, 例如剪切闸板、蓄能器和应急电力系统等。计算两种形式组建的失 效概率公式并不一样，其中连续工作形势组件的失效概率公式如下 ${ }^{[14]}$ 所示:

$$
F_{c}(t)=1-e^{-\lambda t}, t>0
$$

式中: $\lambda$ 为失效频率, 单位为天 ${ }^{-1}$; $\mathrm{t}$ 为组件工作天数, 单位为天。

功能性组件的失效概率计算公式如下 ${ }^{[14]}$ 所示:

$$
F_{o}(t)=1-\frac{1}{\lambda t}\left(1-e^{-\lambda t}\right), t>0
$$

当 $\lambda \cdot \mathrm{t}<10^{-2}$ 时，原式可简化为:

$$
F_{o}(t)=\frac{1}{2} \lambda t, t>0
$$

式中: $\lambda$ 为失效频率，单位为天 ${ }^{-1}$;

$\mathrm{t}$ 为测试周期, 单位为天。

计算过程中做如下假设:

1）防喷器组单井工作时间为60天;

2) 防喷器采用多路电液控制系统, 且测试周期为7天, 一般性组件测试周期为 14 天, 应 急电力系统测试周期为 30 天;

3) 组件在测试周期内发现故障后立即维修或更换且组件状态恢复如新;

4) 水上防喷器组和水下防喷器组的相同组件失效频率一样;

5）平台作业区域海况和天气情况良好。

以ExproSoft发布的数据为基础, 结合相关文献 ${ }^{[15]}$, 按上述方法计算防喷器各组件的先验 概率。

\subsection{SPAR-H人因失误概率计算}

风险分析过程考虑了人因操作失误造成防喷器失效的情况。SPAR-H（Standardized Plant Analysis Risk Human Reliability Analysis Method）是一种人因可靠性分析方法, 最早由美国核

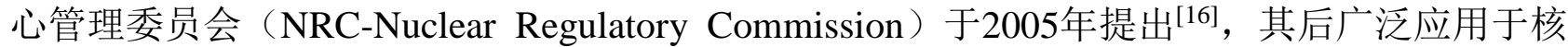
工业中的人因可靠性分析，具有使用简单指标对应清晰等优点 ${ }^{[17]}$ 。由于现场对人因事故的记 录较少且界定模糊, 所以本文将SPAR-H方法引入深水防喷器的人因风险分析中, 综合专家意 见计算人员操作深水防喷器时的人因失误概率（HEP-Human Error Probability）。

在SPAR-H中人因失误概率由名义失误概率（NHEP-Nominal Human Error Probability）和 行为因子（PSFs-Performance Shaping Factors）相乘得出，公式如式（4）所示:

$$
H E P=\frac{\left(N H E P P S F_{\text {composite }}\right)}{N H E P \cdot\left(P S F_{\text {composite }}-1\right)+1}, P S F_{\text {composite }}=\prod_{i}^{8} P S F_{i}
$$

式中: NHEP为名义失误率;

$\mathrm{PSF}_{\text {composite }}$ 为行为形成因子各部分值的乘积。

分析过程中为了得出相对应名义失误概率和行为形成因子，将人的操作分为两个类型。 一类是诊断操作，例如人员判断防喷器闸板是否关闭等; 另一类是执行操作，例如人员执行 关井程序等。对于这两类操作, 名义失误概率赋值分别为 $1 \times 10^{-2}$ 和 $1 \times 10^{-3}$, 而行为形成因子 共包含八个部分，具体指标如表2所示: 
表2 行为形成因子指标

\begin{tabular}{|c|c|c|c|}
\hline \multirow{2}{*}{ 行为形成因子 } & \multirow{2}{*}{ 等级 } & \multicolumn{2}{|c|}{ 标度值 } \\
\hline & & 诊断 & 执行 \\
\hline \multirow{5}{*}{ 可用时间 } & 时间足部（正常时间的 2/3） & \multicolumn{2}{|c|}{10} \\
\hline & 正常时间 & \multicolumn{2}{|c|}{1} \\
\hline & 时间充裕（正常时间的 1 倍和 2 倍之间） & \multicolumn{2}{|c|}{0.1} \\
\hline & 时间很充裕（正常时间的 2 倍以上） & \multicolumn{2}{|c|}{0.01} \\
\hline & 信息不足 & \multicolumn{2}{|c|}{1} \\
\hline \multirow{4}{*}{ 压力 } & 极度紧张 & \multicolumn{2}{|c|}{5} \\
\hline & 压力高 & \multicolumn{2}{|c|}{2} \\
\hline & 正常时间 & \multicolumn{2}{|c|}{1} \\
\hline & 信息不足 & \multicolumn{2}{|c|}{1} \\
\hline \multirow{5}{*}{ 复杂度 } & 非常复杂 & \multicolumn{2}{|c|}{5} \\
\hline & 比较复杂 & \multicolumn{2}{|c|}{2} \\
\hline & 正常 & \multicolumn{2}{|c|}{1} \\
\hline & 简单 & 0.1 & 1 \\
\hline & 信息不足 & \multicolumn{2}{|c|}{1} \\
\hline \multirow{4}{*}{ 经验/培训 } & 缺乏 & 10 & 3 \\
\hline & 正常 & \multicolumn{2}{|c|}{1} \\
\hline & 丰富 & \multicolumn{2}{|c|}{0.5} \\
\hline & 信息不足 & \multicolumn{2}{|c|}{1} \\
\hline \multirow{6}{*}{ 程序 } & 没有程序 & \multicolumn{2}{|c|}{50} \\
\hline & 不完整 & \multicolumn{2}{|c|}{20} \\
\hline & 不完善 & \multicolumn{2}{|c|}{5} \\
\hline & 正常 & \multicolumn{2}{|c|}{1} \\
\hline & 针对具体事件有具体措施 & & \\
\hline & 信息不足 & & 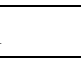 \\
\hline & 缺失 & & 0 \\
\hline & 低 & & 0 \\
\hline 人机交互 & 正常 & & 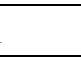 \\
\hline & 高 & & 5 \\
\hline & 信息不足 & & 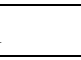 \\
\hline & 勉强胜任 & & 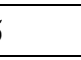 \\
\hline 胜任能力 & 正常 & & 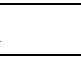 \\
\hline & 信息不足 & & 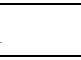 \\
\hline & 未按规定执行 & 2 & 5 \\
\hline & 正常 & 1 & 1 \\
\hline 上作流桯 & 严格执行 & 0.8 & 0.5 \\
\hline & 信息不足 & & \\
\hline
\end{tabular}

结合专家意见和相关文献, 列出防喷器操作过程中可能出现的失误, 并按照表 2 的评价指 标计算人因失误概率。

\section{3 后验概率计算}

以之前计算的水下防喷器组件失效和人因失误概率作为先验概率，利用贝叶斯分析软件 GeNIe贝叶斯网络模型进行分析, 得出水下防喷器组的失效概率为 $8.57 \times 10^{-2}$, 同时利用其逆向 推理能力, 求解各风险诱因的后验概率, 计算结果如表3及图5所示。 
表3 水下防喷器组风险诱因计算

\begin{tabular}{|c|c|c|c|c|}
\hline 种类 & 序号 & 风险诱因 & 先验概率 & 后验概率 \\
\hline \multirow{18}{*}{$\begin{array}{c}\text { 水下防喷器组 } \\
\text { 失效 }\end{array}$} & 1 & 上环形防喷器失效 & $6.51 \mathrm{E}-03$ & $2.23 \mathrm{E}-02$ \\
\hline & 2 & 下环形防喷器失效 & $6.51 \mathrm{E}-03$ & 2.23E-02 \\
\hline & 3 & 人员未按要求停止钻进并将钻柱提到适当位置 & $5.67 \mathrm{E}-02$ & $5.87 \mathrm{E}-02$ \\
\hline & 4 & 人员未能按相关要求执行关井程序 & $9.90 \mathrm{E}-03$ & $9.97 \mathrm{E}-03$ \\
\hline & 5 & 人员未进行溢流检查或决策失误 (软/硬关井) & $9.17 \mathrm{E}-02$ & $9.70 \mathrm{E}-02$ \\
\hline & 6 & 上闸板失效 & $8.83 \mathrm{E}-03$ & $8.83 \mathrm{E}-03$ \\
\hline & 7 & 中闸板失效 & $8.83 \mathrm{E}-03$ & $8.83 \mathrm{E}-03$ \\
\hline & 8 & 下闸板失效 & $8.83 \mathrm{E}-03$ & $8.83 \mathrm{E}-03$ \\
\hline & 9 & 测试闸板失效 & $8.83 \mathrm{E}-03$ & $3.27 \mathrm{E}-02$ \\
\hline & 10 & 人员未将钻柱提升至合适位置关井 & $2.92 \mathrm{E}-02$ & $2.95 \mathrm{E}-02$ \\
\hline & 11 & 人员关井压力解释错误并未能确认是否关井 & $5.03 \mathrm{E}-01$ & 5.10E-01 \\
\hline & 12 & 钻杆剪切闸板失效 & $1.26 \mathrm{E}-02$ & $6.32 \mathrm{E}-02$ \\
\hline & 13 & 套管剪切闸板失效 & $1.26 \mathrm{E}-02$ & $6.32 \mathrm{E}-02$ \\
\hline & 14 & 人员对现场情况误判并延后做出关井决定 & $6.69 \mathrm{E}-01$ & 7.39E-01 \\
\hline & 15 & 人员未按下 EDS 按钮 & $3.75 \mathrm{E}-01$ & 3.84E-01 \\
\hline & 16 & 人员未对 EDS 状态进行监控 & $6.69 \mathrm{E}-01$ & $6.83 \mathrm{E}-01$ \\
\hline & 17 & 人员未能手动利用剪切闸板封井 & $5.46 \mathrm{E}-01$ & $5.56 \mathrm{E}-01$ \\
\hline & 18 & 人员未对手动封井状态监控 & $6.69 \mathrm{E}-01$ & $6.80 \mathrm{E}-01$ \\
\hline \multirow{5}{*}{$\begin{array}{c}\text { 水上控制系统 } \\
\text { 失效 }\end{array}$} & 19 & 蓄能器失效 & $8.33 \mathrm{E}-03$ & $1.46 \mathrm{E}-01$ \\
\hline & 20 & 1 号控制站失效 & 9.97E-03 & $1.13 \mathrm{E}-02$ \\
\hline & 21 & 2 号控制站失效 & 9.97E-03 & $1.13 \mathrm{E}-02$ \\
\hline & 22 & 电力系统失效 & $1.70 \mathrm{E}-02$ & $2.22 \mathrm{E}-01$ \\
\hline & 23 & 应急发电系统失效 & $6.18 \mathrm{E}-03$ & $3.40 \mathrm{E}-02$ \\
\hline \multirow{5}{*}{$\begin{array}{c}\text { 水下控制系统 } \\
\text { 失效 }\end{array}$} & 24 & 蓄能器失效 & $8.33 \mathrm{E}-03$ & $1.95 \mathrm{E}-01$ \\
\hline & 25 & 黄盒失效 & $8.82 \mathrm{E}-03$ & 2.93E-03 \\
\hline & 26 & 蓝盒失效 & $8.82 \mathrm{E}-03$ & $2.93 \mathrm{E}-03$ \\
\hline & 27 & ROV 未能成功操作剪切闸板 & $2.72 \mathrm{E}-03$ & $4.50 \mathrm{E}-02$ \\
\hline & 28 & ROV 领航员操作失误 & $7.50 \mathrm{E}-01$ & $8.02 \mathrm{E}-01$ \\
\hline \multirow{3}{*}{$\begin{array}{c}\text { 节流/压井管 } \\
\text { 线失效 }\end{array}$} & 29 & 节流/压井阀失效 & $1.75 \mathrm{E}-04$ & $1.85 \mathrm{E}-04$ \\
\hline & 30 & 水上管线失效 & $4.65 \mathrm{E}-04$ & 5.44E-04 \\
\hline & 31 & 水下管线失效 & $6.97 \mathrm{E}-03$ & $2.50 \mathrm{E}-02$ \\
\hline \multirow{3}{*}{$\begin{array}{l}\text { 隔水管/井口 } \\
\text { 连接器失效 }\end{array}$} & 32 & 井口连接器失效 & $3.14 \mathrm{E}-02$ & $2.62 \mathrm{E}-01$ \\
\hline & 33 & 隔水管挠性接头失效 & $3.98 \mathrm{E}-03$ & $7.56 \mathrm{E}-03$ \\
\hline & 34 & LMRP 连接器失效 & $1.19 \mathrm{E}-02$ & $4.51 \mathrm{E}-02$ \\
\hline
\end{tabular}




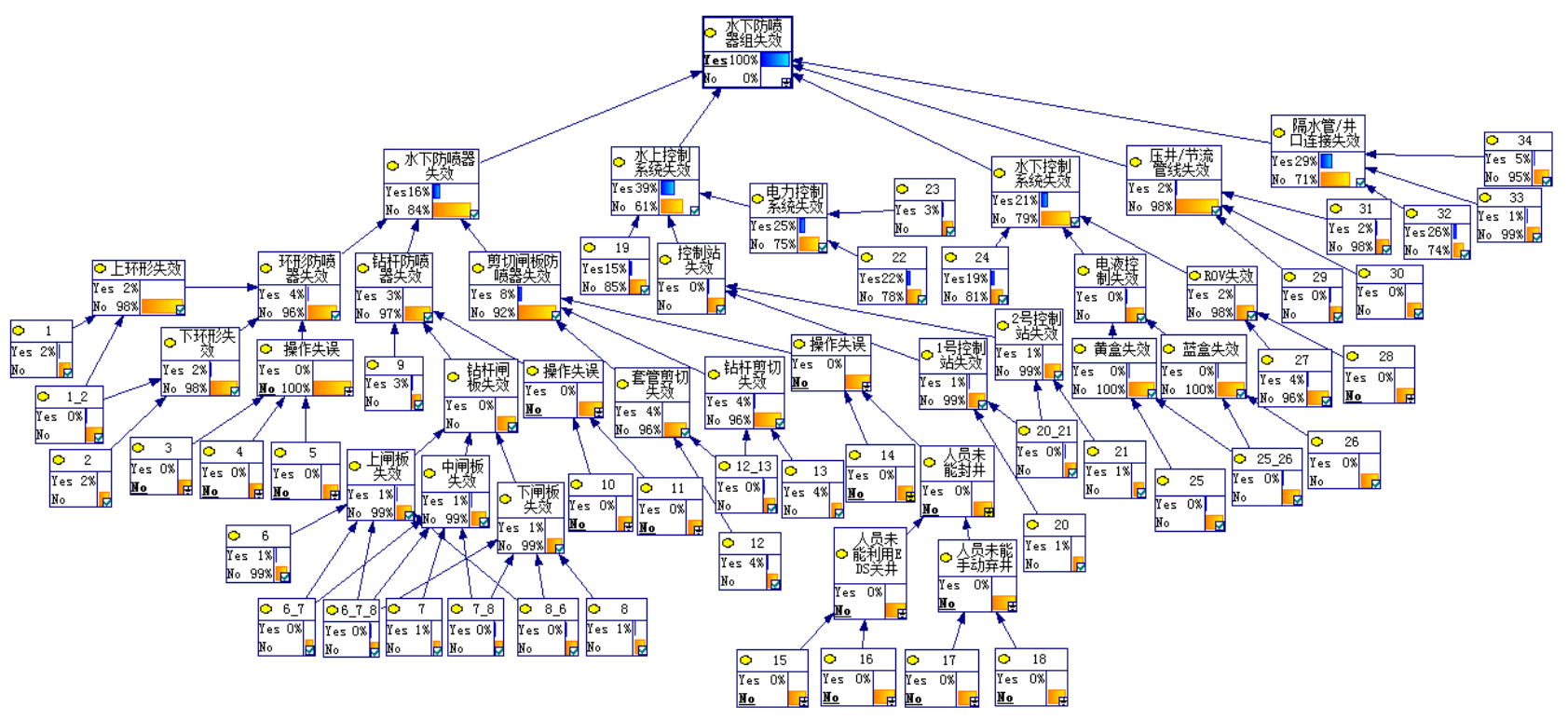

图5 水下防喷器组失效贝叶斯模型

为了更好地分析组件和人因数据找出关键风险诱因, 作出图 6 所示的人因失误概率比值 图和图7所示的组件失效概率差值图。

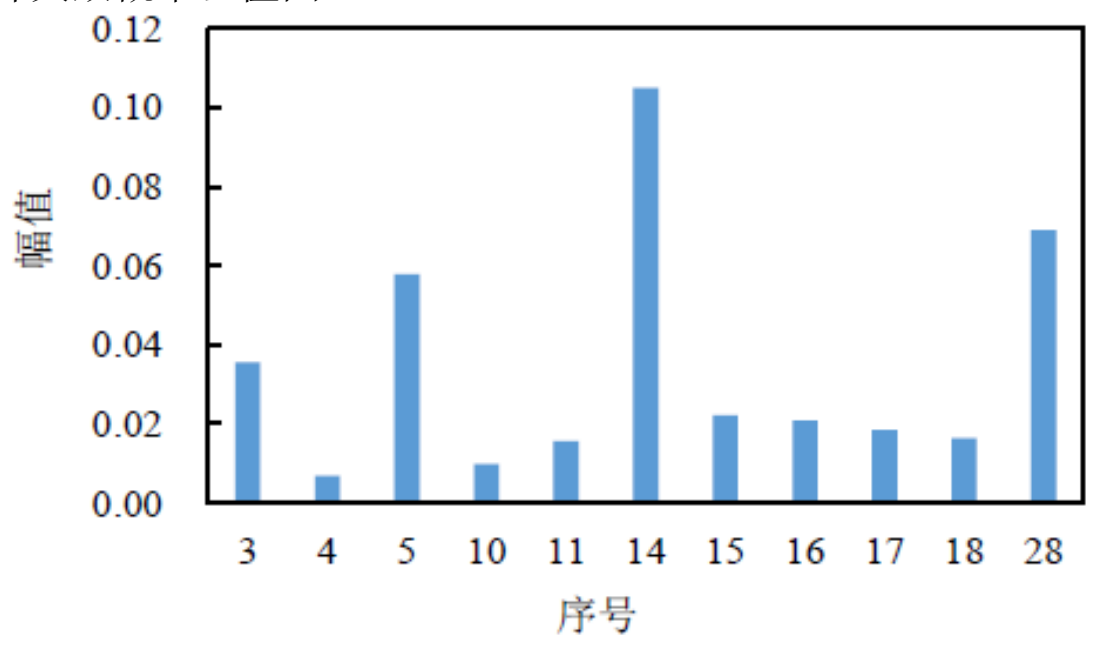

图6 水下防喷器组人因失误概率分析图

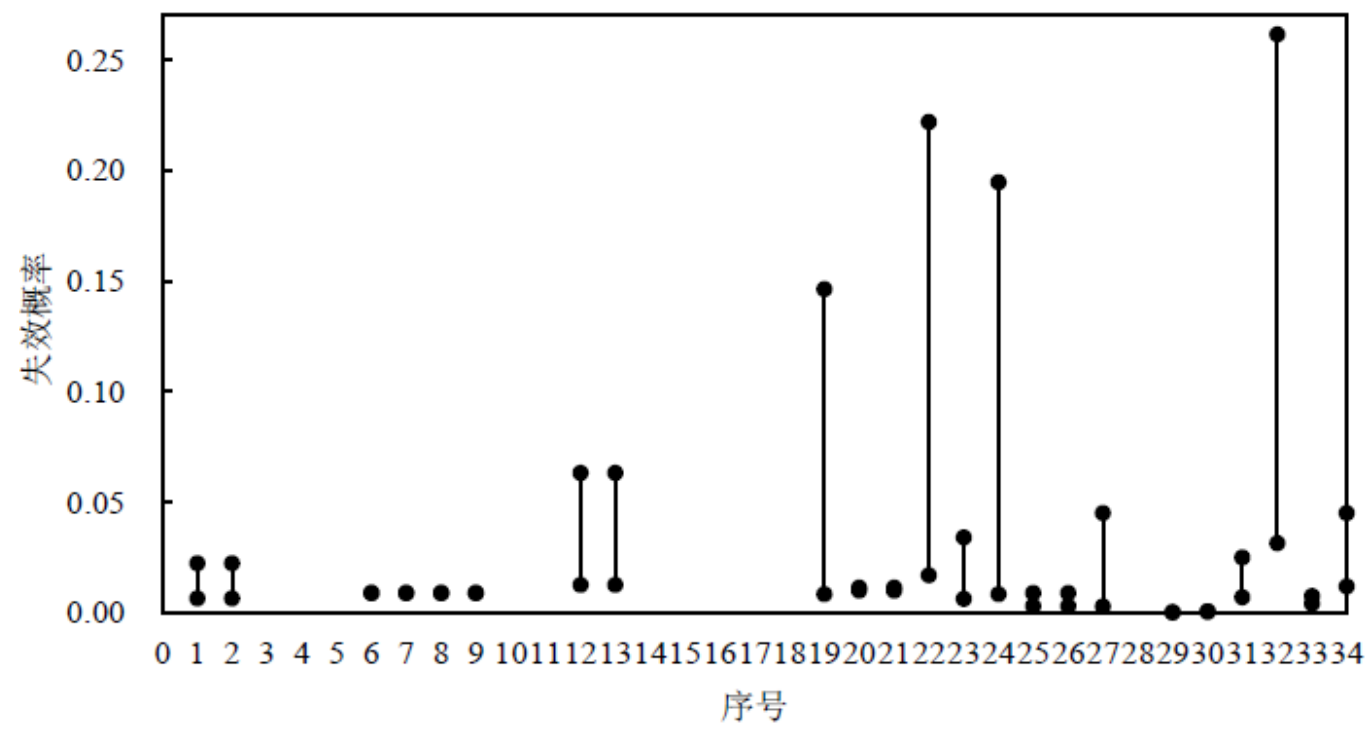

图7 水下防喷器组件失效概率分析图 


\section{4 计算结果分析}

\subsection{1 人员对现场情况误判并延后做出关井决定}

判断失误多因受主观经验及心理定势影响, 或出现危险事件所造成的紧张状态所致。在 井涌形成井喷的过程中, 大量液体从井口喷涌而出, 势必对人员构成很大的心理压力。此类 风险诱因发生概率大, 说明需要加强作业人员在危险状态下的安全操作技能训练, 在关键时 刻临危不乱。

\subsubsection{ROV领航员操作失误}

操作失误主要是由于技术不熟练或操作困难，特别是当意识水平低下或疲劳时，这种失 误更易发生。此类风险诱因发生概率较大, 说明需要加强现场ROV领航员的培训, 并多加关 注其身心健康状态。

\subsection{3 井口连接器失效}

井口连接器用于将防喷器组连接到水下井口上，由于安装失误、腐蚀、磨损、老化等因 素会导致密封失效和解锁失效。应定期检查液压连接器在最低开启和关闭压力下能否正常工 作及钢圈锁销的工作状态，保证其可靠性。

\subsection{4 电力系统失效}

电力系统的发电机、变压器、输电线路等各种设备, 都有可能在运行中发生不同类型的 故障, 影响电力系统的正常运行。应最大限度的提高电力系统的生存能力, 采用防爆电路, 并配备防爆防火墙。

\subsection{5 蓄能器失效}

蓄能器作为防喷器的开关动力源, 是控制系统的关键设备。为有效控制此类风险诱因, 应检查蓄能器内预充气体是否为氮气且压力是否高于 $7 \mathrm{MPa}$, 并保证关闭所有防喷器后, 蓄能 器内剩余压力大于关闭任何一个闸板防喷器所需的最小操作压力。

4.4.6剪切闸板失效

剪切闸板需在必要情况下切断作业管柱以实现全封, 失效将导致作业管柱不能及时脱离、 封井失败等严重后果。应在钻前设备配置阶段, 预估切断作业所需剪切力, 评估闸板的剪切 能力, 保证密封效果。

\section{5. 结束语}

1）深水水下防喷器包含 6 个主要失效原因。其中人员对现场情况误判并延后做出关井决 定和ROV领航员操作失误属于人因失误, 井口连接器失效、电力系统失效、蓄能器失效和剪 切板失效属于组件失效。

2) 对比人因失误概率和组件失效概率可以看出, 在保证深水水下防喷器各部件安全可靠 的同时也要注重人员素质方面的提高。

\section{致谢}

本文为国家重点基础研究发展计划（973计划）“海洋深水油气安全高效钻完井基础”的 阶段性成果之一。

\section{References}

[1] Jiang Wei. Deepwater drilling and completion technology of China National Offshore Oil Corporation[J]. Oil Drilling and Production Technology, 2015,37 (1) : 1-4

[2] Yang Jinhua,Guo Xiaoxia. Momentum of Worldwide Deepwater Oil and Gas Exploration and Development[J]. Oil Forum, 2014,33 (5): 49-55. 
[3] Cao Shijing. Analysis on the reliability of subsea BOP and control system for ultra-deepwater drilling unit HYSY981[J]. China Offshore Oil and Gas,2013,25(01):46-48

[4] Per Holand. Reliability of Subsea BOP Systems for Deepwater Application, Phase II DW[R]. Trondheim: SINTEF,1999.

[5] Per Holand, Hammad Awan. Reliability of Deepwater Subsea BOP Systems and Well Kicks[R]. Trondheim: ExproSoft AS,2012.

[6] Sondre Klakegg. Improved methods for reliability assessments of safety-critical systems: An application example for BOP systems[D]. Trondheim:Norwegian University of Science and Technology,2012.

[7] Elisabeth Drægebø. Reliability Analysis of Blowout Preventer Systems [D]. Trondheim:Norwegian University of Science and Technology,2014.

[8] Per Holand, Hammad Awan. Reliability of Deepwater Subsea BOP Systems and Well Kicks[R]. Trondheim: ExproSoft AS,2012.

[9] International Association of Drilling Contractors. Deepwater Well Control Guidelines[M]. 2nd Edition. Houston: International Association of Drilling Contractors,2015.

[10]Liu Shujie,Li Xiangfang. Reliability analysis on safety barriers of deep-water drilling based on Bayesian-LOPA method[J]. Journal of Safety Science and Technology, 2014,10(9):187-191.

[11]Jorge Luis Meléndez. Risk Assessment of Surface vs. Subsea Blowout Preventers（BOPs） on Mobile Offshore Drilling Units Focusing on Riser Failure and the Use of Subsea Shear Rams[D]. Texas:Texas A\&M University,2006.

[12]Baoping Cai, Yonghong Liu, Zengkai Liu, et al. Performance evaluation of subsea blowout preventer systems with common-cause failures[J]. Journal of Petroleum Science and Engineering,2012,90(4) : 18-25.

[13]Zhou Zhongbao. Probabilistic Safety Assessment Research Based on Bayesian Networks[D].ChangSha: National University of Defense Technology,2006

[14]D.J Smith. Reliability Maintainability and Risk[M]. 7th Edition. Oxford: Elsevier,2005.

[15]OREDA.Offshore Reliability Data Handbook [M].Trondheim : Det Norske Veritas, 2002.

[16]D. Gertman, H.S. Blackman, J. Marble, et al. The SPAR-H human reliability analysis method[R]. Washington, DC:Nuclear Regulatory Commission,2005.

[17] Wu You. The Application of TACOM Method in SPAR-H[D]. TianJin: Tianjin University,2013 